\title{
THE LONG-TERM RESULTS OF WATSON-JONES TENODESIS
}

\author{
A. J. VAN DER RIJT, GWYN A. EVANS
}

From the Robert Jones and Agnes Hunt Orthopaedic Hospital, Oswestry

\begin{abstract}
Nine patients have been reviewed at an average period of 22 years after a Watson-Jones tenodesis performed for chronic instability of the ankle. Only three patients had complete relief of symptoms. Two favourable early results deteriorated 7 and 10 years after operation. Radiographic examination revealed full correction of both anterior and lateral instability of the talus in only two cases. Talar tilt was controlled more successfully than increased anterior drawer movement. Long-standing instability was associated with the formation of marginal exostoses, the severity of which appeared proportional to the degree of instability.
\end{abstract}

Chronic instability of the ankle may occur after an injury to the lateral ligament (Broström 1966; Chrisman and Snook 1969) or, less commonly, in patients with symmetrical hypermobility of the ankle in association with generalised joint laxity (Bonnin 1944; Evans 1953). The patient experiences a feeling of insecurity when walking on uneven surfaces or playing games. This may be associated with sudden inversion of the foot described as "giving way" or, in its severest form, recurrent episodes of ankle sprain with pain, swelling and loss of function. This symptom-complex may result from the ruptured ligament healing in an attenuated state with consequent increased mobility of the talus in the ankle mortise. The rationale for treatment by tenodesis is that the hypermobility of the talus can be controlled by reinforcing the structures on the lateral aspect of the joint.

The Watson-Jones tenodesis was designed to correct instability arising from incompetence of both the anterior talofibular and calcaneofibular ligaments (Watson-Jones 1955). It accurately reproduces the direction of the anterior talofibular ligament (Kelley and Janes 1956; Laurin, Ouellet and St-Jacques 1968; Gillespie and Boucher 1971), but the reconstructed calcaneofibular ligament is at right angles to the line of the original ligament (Broström 1966; Chrisman and Snook 1969). Many reports on the Watson-Jones tenodesis, and other operations designed to correct functional instability, give favourable results which are based on a short period of follow-up. The longest period for review in the literature of a standard Watson-Jones tenodesis is reported by Gillespie and Boucher (1971). At an average follow-up of six years they found one patient out of 20 with persistent functional instability, and all the ankles were radiograph-

A. J. van der Rijt, MB BS, Registrar

G. A. Evans, FRCS, FRCS Ed (Orth), Consultant

Robert Jones and Agnes Hunt Orthopaedic Hospital, Oswestry, Salop S710 7AG, England.

Requests for reprints should be sent to Mr G. A. Evans.

(C) 1984 British Editorial Society of Bone and Joint Surgery

$0301-620 \times / 84 / 3072 \$ 2.00$ ically stable. We report a much longer follow-up of Watson-Jones tenodesis performed to control symptomatic and radiographically demonstrable instability of the ankle.

\section{MATERIALS AND METHODS}

Nine patients, six male and three female, were able to attend for review (Table I). The average follow-up after a standard Watson-Jones tenodesis was 22 years, with a range of 12 to 27 years. All patients had presented initially with recurrent inversion injuries of the ankle, the average duration of symptoms being 4.6 years ( 1.5 to 11 years). Stress inversion radiographs were performed under general anaesthesia before operation and the presence of abnormal talar tilt confirmed in the clinical record. Unfortunately the old radiographs had been destroyed. The average age at the time of operation was 32 years, with a range of 19 to 40 years. The right ankle had been operated upon in five patients and the left ankle in four. One patient had bilateral functional instability, but a Watson-Jones tenodesis had been performed on one side only.

The clinical review included specific questions concerning pain, swelling, stiffness, difficulty walking on uneven ground, and episodes of "giving way" or recurrent sprains. Also recorded were the occupation, sporting activity, necessity for wearing an ankle support, and the height and width of heel worn. Any change in the condition of the ankle with time was recorded. Examination included comparison with the opposite ankle and foot for appearance, tenderness, range of movement, joint stability, and the power of eversion. Generalised hypermobility of joints was noted.

Radiographic examination included stress inversion views with the ankle medially rotated to produce a neutral position of the mortise, and anterior drawer views with the foot held both in $30^{\circ}$ of plantarflexion and at a right angle to the leg. Both ankles were included in the examination. A steadily increasing force was applied by 


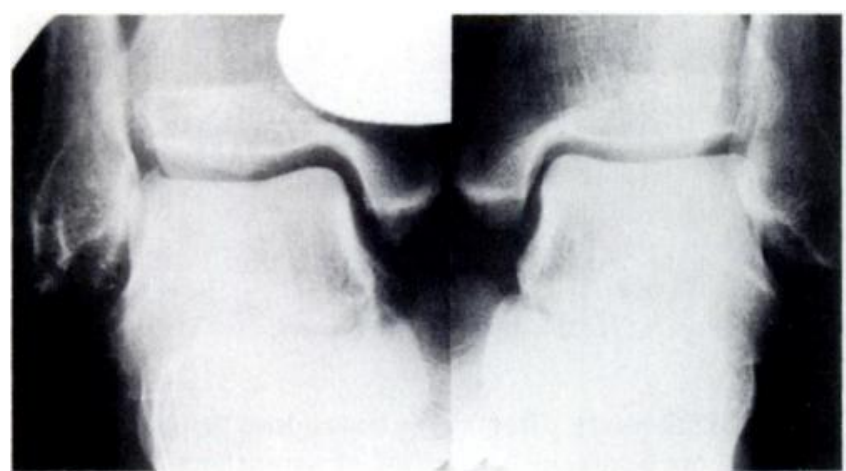

Fig. I

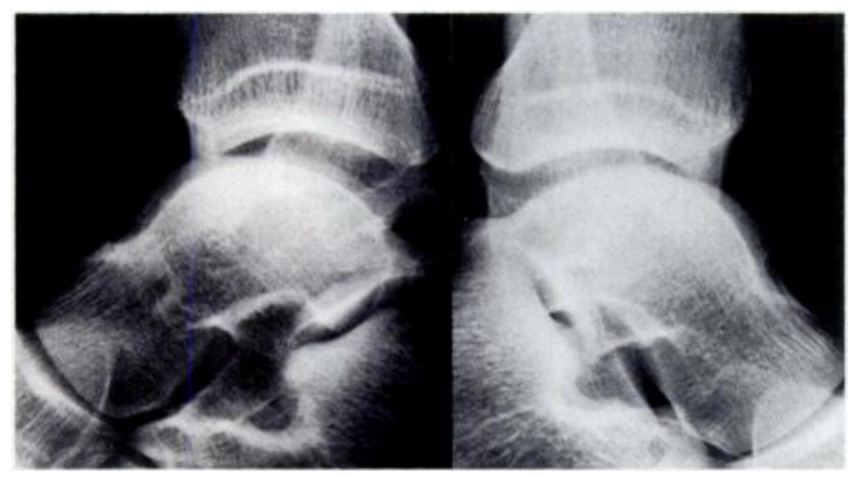

Fig. 2

the examiner's gloved hand for a period of one minute. With the exception of one patient, who had recently suffered a resprain of the ankle, this examination did not cause discomfort or muscle spasm. These methods produce accurate results, comparable with the application of a fixed force to a foot held in a restraining device (Laurin et al. 1968; Laurin and Mathieu 1975). The assessment was performed by one examiner in an attempt to minimise observer variability.

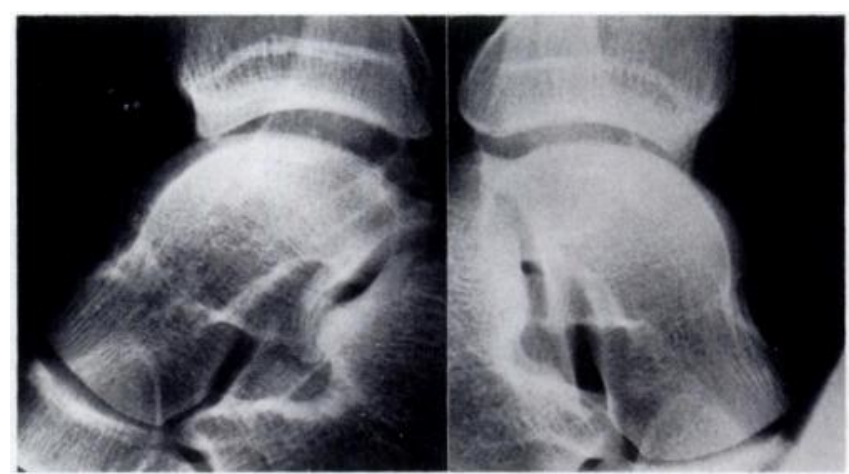

Fig. 3

Case I. Radiographs of both ankles of a 45-year-old man. 27 years after a right Watson-Jones tenodesis. Talar tilt is controlled but an abnormal anterior drawer has persisted. Figure I Stress inversion radiographs. Figure 2-Anterior drawer movement with the foot plantigrade. Figure 3 Anterior drawer in equinus.

\section{RESULTS}

At review there were only three symptom-free patients (Table I), of whom two were employed in occupations which placed maximal demand on the stability of the ankle: one was an engineer on a construction site (Figs 1 to 3), and the other a gamekeeper. The remaining six patients experienced some difficulties while walking on irregular surfaces. This was limited to a feeling of insecurity in two, episodes of "giving way" in two, and the remaining two patients had suffered recurrent painful sprains (Table I). Two patients (Cases 4 and 6) had pain which was not associated with recurrent sprains, one arising from the ankle joint and the other from a tender neuroma. Two more patients (Cases 2 and 4) complained of minor stiffness, and the two symptomatic women were unable to wear high-heel shoes because of an increased feeling of insecurity while walking. One patient (Case 3) wore lace-up boots at work to control the ankle.

Table I. Clinical details with the result of stress radiographs

\begin{tabular}{|c|c|c|c|c|c|c|c|c|c|c|}
\hline \multirow[b]{3}{*}{ Case } & \multirow[b]{3}{*}{ Sex } & \multirow{3}{*}{$\begin{array}{l}\text { Age at } \\
\text { operation } \\
\text { (years) }\end{array}$} & \multirow[b]{3}{*}{$\begin{array}{l}\text { Follow-up } \\
\text { (years) }\end{array}$} & \multirow[b]{3}{*}{ Symptoms } & \multirow{2}{*}{\multicolumn{2}{|c|}{ Talar tilt (degrees) }} & \multicolumn{4}{|c|}{ Anterior drawer ( $\mathrm{mm}$ ) } \\
\hline & & & & & & & \multicolumn{2}{|c|}{ Plantigrade } & \multicolumn{2}{|l|}{ Equinus } \\
\hline & & & & & Tenodesis & $\begin{array}{l}\text { Opposite } \\
\text { ankle }\end{array}$ & Tenodesis & $\begin{array}{l}\text { Opposite } \\
\text { ankle }\end{array}$ & Tenodesis & $\begin{array}{l}\text { Opposite } \\
\text { ankle }\end{array}$ \\
\hline 1 & $\mathbf{M}$ & 19 & 27 & None & 3 & 2 & 10 & 5 & 8 & 4 \\
\hline 2 & $\mathrm{~F}$ & 40 & 21 & Giving way & 8 & 15 & 5 & 3 & 8 & 5 \\
\hline 3 & $\mathbf{M}$ & 32 & 15 & Giving way & 17 & 4 & 9 & 5 & 8 & 4 \\
\hline 4 & $\mathbf{M}$ & 40 & 27 & Insecure & 21 & 13 & 6 & 6 & 7 & 6 \\
\hline 5 & $\mathbf{M}$ & 32 & 22 & Insecure & 4 & 2 & 7 & 4 & 4 & 7 \\
\hline $6^{*}$ & $\mathbf{M}$ & 28 & 24 & Recurrent sprains & 12 & 21 & 4 & 8 & 4 & 7 \\
\hline 7 & $\mathrm{~F}$ & 36 & 25 & Recurrent sprains & 5 & 10 & 8 & 4 & 8 & 4 \\
\hline $8^{*}$ & $\mathbf{M}$ & 31 & 25 & None & 5 & 13 & 5 & 8 & 6 & 6 \\
\hline 9 & $\mathrm{~F}$ & 32 & 12 & None & 2 & 3 & 6 & 1 & 7 & 2 \\
\hline
\end{tabular}

The symptoms recorded include a subjective sensation of insecurity while walking on uneven ground, repeated giving way, or recurrent sprains * History of bilateral injury and functional instability 


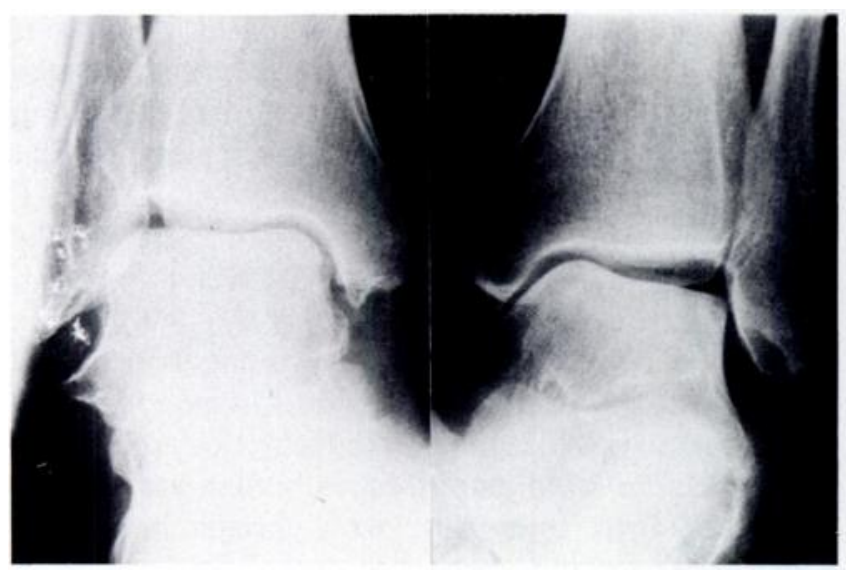

Fig. 4

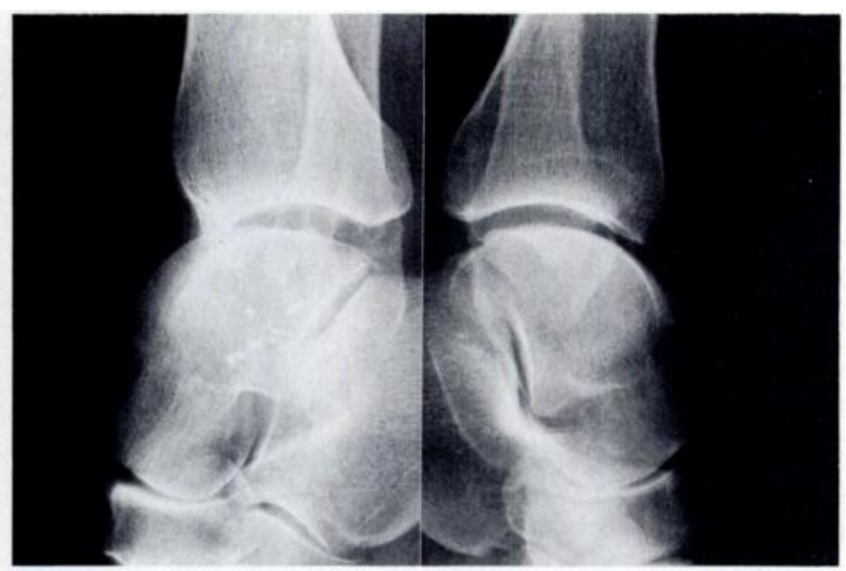

Fig. 5

Case 2. Radiographs of both ankles 21 years after tenodesis on the right. Figure 4-The talar tilt has been controlled. A medial malleolar exostosis and a superolateral talar cyst are present on the right. Figure 5-Anterior instability persists.

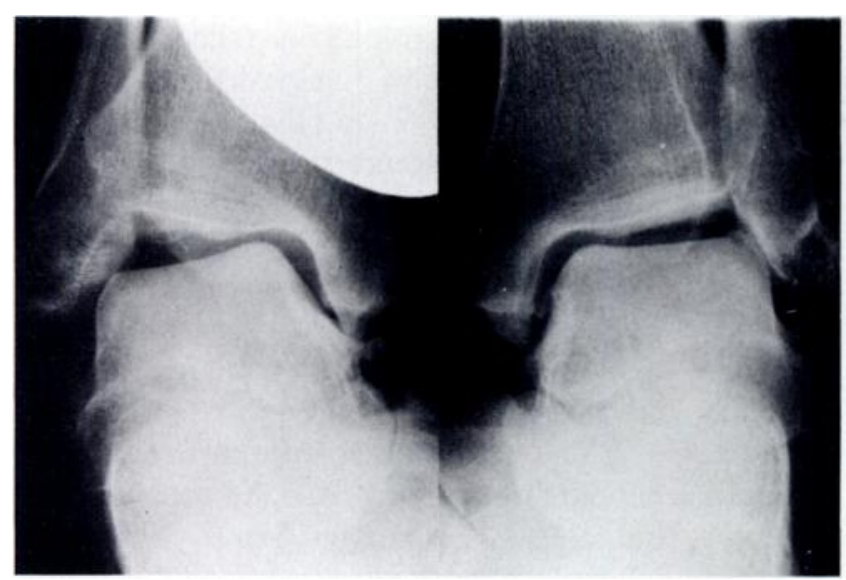

Fig. 6

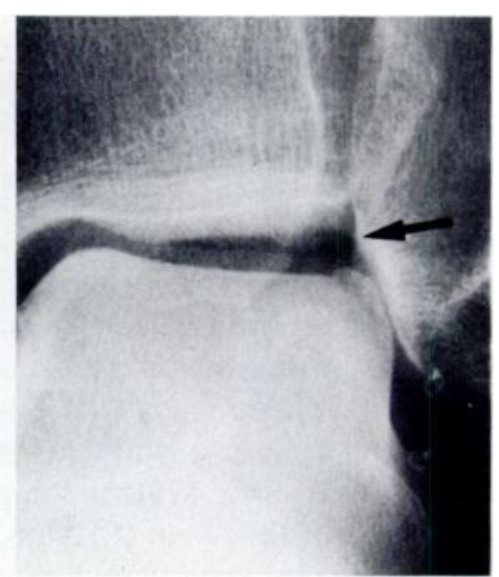

Fig. 7

Case 6. Radiographs of a 52-year-old coalminer with persistent symptoms, 24 years after presenting with bilateral functional instability and undergoing unilateral tenodesis on the left. Figure 6-There are bilateral exostoses. The tilt is more marked on the unoperated side. Figure 7-The vacuum stress arthrogram (arrow) on the tenodesed side also demonstrates a bony prominence at the superolateral corner and slight thinning of the medial articular cartilage on the superior talar surface.

Clinical examination. Four patients (Cases 1, 2, 8 and 9) had normal ankles without swelling, tenderness or restriction of movement. The remaining patients had slight fullness over the region of the lateral malleolus, and three patients (Cases 4,6 and 7) had local tenderness. All but one patient displayed full movement in the ankle, subtalar and midtarsal joints. The only patient with limitation of inversion had suffered a recent sprain. There was no evidence of generalised joint hypermobility. Complications. Postoperative problems occurred in two patients: one had a neuroma with paraesthesia in the lateral toes, and one had a minor stitch abscess which healed uneventfully.

Occupation. None of the patients changed employment because of ankle symptoms. There were two coalminers, a gamekeeper, carpenter, painter, and a mechanical engineer. One woman worked as a school-teacher, another was a farmer's wife and the third suffered from epilepsy and was unemployed. Only one patient (Case 1) had played football before operation, and he was able to continue and was still active in training a football team.
Radiological assessment. The measurements made on stress radiography are documented in Table I. Talar tilt was more successfully controlled than increased anterior drawer (Figs 1 to 3). Failure to control talar tilt occurred in two patients (Cases 3 and 4), both complaining of functional instability. All three asymptomatic patients had normal stress inversion radiographs. An asymmetrical increase of anterior drawer was noted in six patients (Figs 2 and 5). This was controlled in a position of equinus in one patient only, and in the other cases there was no appreciable difference with the foot held plantigrade or in equinus (Figs 2 and 3). There was no obvious correlation between symptoms and abnormal anterior drawer.

Marginal exostoses were present in all operated ankles (Figs 1 to 7 ). The changes varied from a minimal exostosis at the tip of the medial or lateral malleolus, to widespread exostoses on both malleoli and the anterior and posterior articular margins of the tibia. The severity appeared to correlate with the degree of talar instability. There were four cases with similar changes in the 
contralateral ankle (Fig. 6) which again appeared to correlate with the degree of talar instability. There was no clear relationship between the exostoses and the symptoms described. A bony prominence was noted at the superolateral corner of the talar articular surface in three patients (Figs 1 and 7), and a subchondral cyst at the same site in another patient (Fig. 4). On one occasion the vacuum effect on the stress inversion radiograph appeared to show slight thinning of the superomedial articular cartilage (Fig. 7).

Long-term function. Four patients had total relief of symptoms after operation, of whom two developed late problems. One resprained the ankle seven years later, which resulted in functional instability, and the other gradually deteriorated after 10 years and suffered recurrent sprains. Three patients felt that their ankle function had gradually improved over the first five or six years after tenodesis and then remained static. Two patients continued to suffer from insecurity and occasional "giving way" immediately after operation, and this had persisted.

\section{DISCUSSION}

This long-term review of Watson-Jones tenodesis shows a significant number of results which are unsatisfactory both clinically and radiographically. Six of the nine patients reviewed had persisting symptoms of functional instability. Previous series of Watson-Jones tenodesis with a shorter period of follow-up (Clayton, Trott and Ulin 1951; Anderson and Lecocq 1954; Kelley and Janes 1956; Gillespie and Boucher 1971) have reported excellent control of functional instability. Similar results, with short periods of follow-up, have been reported for a modified Watson-Jones tenodesis (Lee 1957; Boghemans 1968), modified Elmslie repair (Chrisman and Snook 1969), free tendon graft (Sefton et al. 1979), ligamentoplasty (Landeros, Frost and Higgins 1968), Evans repair (Evans 1953), and secondary suture of the ruptured ligament (Broström 1966).

Two of the unsatisfactory results in this present series occurred after initial success, the patients developing further instability 7 and 10 years after operation. One may have been due to rupture of the tenodesis by a further sprain. These late deteriorations occurred outside the period for review of most past reports, and it appears that early success is not a guarantee of continuing ankle stability. Tindall and Heaney (1976) described two patients who, after initial symptomatic benefit, developed functional instability after the Evans repair. They did not report how long after operation these failures occurred. No other paper refers to this as a problem.

A significant number of patients had persistent radiographic hypermobility in one or both of the planes examined. While most reports have documented excellent functional results, few authors have included stress radiography in their assessment. Gillespie and Boucher
(1971) found talar tilt was controlled in all 20 patients reviewed after Watson-Jones tenodesis and Chrisman and Snook (1969) showed excellent control of talar tilt in seven patients with modified Elmslie repair. Neither report investigated anterior instability.

In this study talar tilt was more successfully controlled than increased anterior drawer movement. Contrary to the opinion of Landeros et al. (1968), in five out of six patients the drawer sign was not abolished by placing the foot in $30^{\circ}$ plantarflexion. Glasgow, Jackson and Jamieson (1980) confirmed that anterior subluxation can be demonstrated more frequently than varus laxity both after acute injury and with chronic instability. Anterior drawer movement is controlled by the anterior talofibular ligament. Although the Watson-Jones tenodesis was designed specifically to reconstruct this ligament, it appears that in most cases the tenodesis was either too slack initially or failed with time. The Evans procedure has now superseded the Watson-Jones tenodesis (Colton 1982), but the design of the operation is no more likely to secure the talus against anterior drawer movement, as the tendon is not specifically inserted into the talus. Tindall and Heaney (1976) report that only $46 \%$ of patients in their series were free of symptoms after the Evans tenodesis, and with a longer follow-up it is possible that there may be further failures, as in this series of Watson-Jones tenodesis.

The consistent feature in the three asymptomatic patients in our study was the correction of varus tilt of the talus. Chrisman and Snook (1969) have shown that talar tilt is more effectively controlled by the modified Elmslie repair than by the Watson-Jones or Evans tenodesis. Their technique of fixation therefore seems to be preferable, although the split peroneus brevis tendon may be relatively weak and predispose to late recurrence of symptoms. The use of flexible carbon fibre implants (Jenkins and McKibbin 1980) may resolve this problem.

It is clear that the symptoms of chronic instability of the ankle after lateral ligament rupture are not entirely resolved by tenodesis, and our main objective should therefore be effective primary treatment of the injury. In this respect, appropriate immobilisation of the ankle in a plaster cast appears to give as good long-term results as primary surgical repair of the ligament, and without the operative morbidity (Evans, Hardcastle and Frenyo 1984).

There was a high incidence of exostosis formation in the ankles reviewed. These changes occurred to some degree in all the tenodesed ankles, the appearance being most marked in the ankles with the greatest laxity. Harrington (1979) felt that medial malleolar and medial talar spurs are the earliest indication of osteoarthritis, associated with the complaint of pain in the anterior or medial part of the joint which is aggravated by walking. $\mathrm{He}$ found that radiographs taken while weight-bearing show loss of medial joint space in these cases and demonstrated chondromalacia or frank loss of articular 
cartilage at arthroscopy. None of our patients gave a similar history of pain, and there were no clinical findings to support a diagnosis of osteoarthritis. We did not take films while weight-bearing but one patient demonstrated probable slight thinning of the medial talar articular cartilage, seen by the vacuum effect on stress radiography (Fig. 7). This was associated with 24 years of persistent instability after tenodesis.
It therefore appears that the symptoms and radiographic features of osteoarthritis of the ankle take very many years to develop. The severity of changes seen in this series appeared proportional to the degree of hypermobility, and this supports the concept that an early and effective tenodesis will correct the abnormal mechanics and prevent the progression of the degenerative process (Harrington 1979).

These long-term reviews would not have been possible without the careful indexing of cases by $\mathrm{Mr} \mathrm{J}$. Rowland Hughes, to whom we are very grateful.

\section{REFERENCES}

Anderson KJ, Lecocq JF. Operative treatment of injury to the fibular collateral ligament of the ankle. J Bone Joint Surg [ Am] 1954:36-A :825-32. Boghemans J. Rupture of the lateral ligament of the ankle. J Bone Joint Surg [Br] 1968;50-B:887.

Bonnin JG. The hypermobile ankle. Proc R Soc Med 1944;37:282-6.

Broström L. Sprained ankles: VI-Surgical treatment of "chronic" ligament ruptures. Acta Chir Scand 1966:132:551-65.

Chrisman OD, Snook GA. Reconstruction of lateral ligament tears of the ankle : an experimental study and clinical evaluation of seven patients treated by a new modification of the Elmslie procedure. J Bone Joint Surg [ Am] 1969;51-A :904-12.

Clayton ML, Trott AW, Ulin R. Recurrent subluxation of the ankle: with special reference to peroneal-nerve block as a diagnostic aid. $J$ Bone Joint Surg [Am] $1951 ; 33-\mathrm{A}: 502-4$.

Colton CL. Injuries of the ankle. In: Wilson JN, ed. Watson-Jones fractures and joint injuries. 6th ed. Edinburgh, London, Melbourne, New York: Churchill Livingstone, 1982:2:1104-51.

Evans DL. Recurrent instability of the ankle: a method of surgical treatment. Proc $R$ Soc Med 1953:46:343-4.

Evans GA, Hardcastle P, Frenyo AD. Acute rupture of the lateral ligament of the ankle: to suture or not to suture? J Bone Joint Surg [Br] 1984; 66-B:209-12.

Gillespie HS, Boucher P. Watson-Jones repair of lateral instability of the ankle. J Bone Joint Surg [Am] 1971;53-A :920-4.

Glasgow M, Jackson A, Jamieson AM. Instability of the ankle after injury to the lateral ligament. J Bone Joint Surg [Br] 1980;62-B: 196-200.

Harrington KD. Degenerative arthritis of the ankle secondary to long-standing lateral ligament instability. J Bone Joint Surg [Am] 1979; 61-A:354-61.

Jenkins DHR, McKibbin B. The role of flexible carbon-fibre implants as tendon and ligament substitutes in clinical practice : a preliminary report. J Bone Joint Surg [Br] 1980;62-B:497-9.

Kelley JH, Janes JM. The chronic subluxating ankle. Arch Surg 1956;72:618-21.

Landeros O, Frost HM, Higgins CC. Post-traumatic anterior ankle instability. Clin Orthop 1968;56:169-78.

Laurin C, Mathieu J. Sagittal mobility of the normal ankle. Clin Orthop 1975; 108:99-104.

Laurin CA, Ouellet R, St-Jacques R. Talar and subtalar tilt: an experimental investigation. Can J Surg 1968;11:270-9.

Lee JG. Surgical repair in recurrent dislocation of the ankle joint. J Bone Joint Surg [Am] 1957:39-A:828-34.

Sefton GK, George J, Fitton JM, McMullen H. Reconstruction of the anterior talofibular ligament for the treatment of the unstable ankle. $J$ Bone Joint Surg [Br] 1979:61-B:352-4.

Tindall SF, Heaney SH. Repair of the lateral ligaments of the ankle by the Evans technique. J Bone Joint Surg [Br] 1976;58-B: 133.

Watson-Jones Sir R. Fractures and joint injuries. 4th ed. Edinburgh and London: E \& S Livingstone, 1955;2:821-3. 